\title{
Influence of Vibrational Loading on Deformation Behavior of Metallic Glass: A Molecular Dynamics Study
}

\author{
Mao Zhang ${ }^{1}$, Qiaomin $\mathrm{Li}^{2}{ }^{2}$, Jiacheng Zhang ${ }^{1}$, Xinyun Wang ${ }^{1}$, Junsong Jin ${ }^{1}$, Pan Gong ${ }^{1}$ and \\ Lei Deng ${ }^{1, *}$ \\ 1 State Key Laboratory of Materials Processing and Die \& Mould Technology, Huazhong University of Science \\ and Technology, 1037 Luoyu Road, Wuhan 430074, China; zhangm@hust.edu.cn (M.Z.); \\ zhangjiacheng2011@gmail.com (J.Z.); wangxy_hust@163.com (X.W.); jjjin@hust.edu.cn (J.J.); \\ gongpan126@126.com (P.G.) \\ 2 Hubei Provincial Engineering Research Center of Industrial Detonator Intelligent Assembly, Wuhan Textile \\ University, 1 Yangguang Avenue, Wuhan 430073, China; qmli@wtu.edu.cn \\ * Correspondence: denglei@hust.edu.cn; Tel./Fax: +86-27-8754-3676
}

Received: 18 October 2019; Accepted: 6 November 2019; Published: 7 November 2019

\begin{abstract}
The influence of vibrational loading on the deformation behavior of a $\mathrm{Zr}_{50} \mathrm{Cu}_{46} \mathrm{Al}_{4}$ metallic glass (MG) was characterized via molecular dynamics approaches. High-frequency $(1 \mathrm{GHz})$ vibrational loading was imposed on the elastoplastic deformation stage during the uniaxial tension of the MG conducted at $50 \mathrm{~K}$. It was found that imposing vibrational loading scarcely reduces the average deformation resistance. On the contrary, it results in a notable residual hardening effect after the vibrational loading is removed, which differs significantly from the previously reported acoustic softening mechanisms. Vibrational loading can increase the fraction of STZed atoms and enhance the shear localization degree, which is beneficial to the shear deformation of MGs. Meanwhile, the influence of vibrational loading on the local microstructure of MG is negligible. A plausible explanation of these phenomena is given by considering the accelerated aging of MG stemming from the $\beta$ relaxation.
\end{abstract}

Keywords: vibrational loading; metallic glass; molecular dynamics simulation; residual hardening; aging

\section{Introduction}

Metallic glasses (MGs) are a new type of material with long-range disorder of internal atomic arrangement. They have excellent mechanical properties such as high strength, high elasticity, strong corrosion resistance and wear resistance [1-3]. Moreover, MGs present favorable superplasticity at elevated temperatures and their volume shrinkage during thermoplastic forming is only $0.2 \%$. Hence, the net-shape forming of high-precision and defect-free parts can be produced via the thermoplastic forming (TPF) of MGs [4].

According to previous studies, MGs are highly susceptible to oxidation during TPF [5]. Oxidation significantly changes the structures and properties of MGs, which in turn makes the TPF processes and final products of MGs deviate from the design goal [6,7]. Therefore, it is necessary to improve existing TPF processes and develop new methods to eliminate as much as possible the effects of oxidation on MG TPF processes and products [8].

Vibrational loading can not only significantly reduce material deformation resistance but also greatly increase the surface quality and forming limit of parts [9-11]. Hence, vibrational loading has significant application potentials in fields like increasing the efficiency of metal plastic forming and 
achieving the forming of difficult-to-deform materials $[12,13]$. The application of ultrasonic vibration in MG TPF is still at the exploration stage. Li et al. confirmed that even with low-frequency vibration $\left(f<10 \mathrm{~Hz}\right.$ ), the TPF ability of $\mathrm{Zr}_{35} \mathrm{Ti}_{30} \mathrm{Cu}_{8.25} \mathrm{Be}_{26.75}$ metallic glass can be significantly enhanced, and the formability increases with the increase of vibration frequency [14]. In order to reduce the oxidation and crystallization of metallic glass during TPF, Ma et al. used ultrasonic hitting frictional heat to replace the traditional heating mode, so that $\mathrm{Zr}_{35} \mathrm{Ti}_{30} \mathrm{Cu}_{8.25} \mathrm{Be}_{26.75}$ metallic glass can soften and deform in sub-second time [15]. From these studies, we can see that by introducing vibrational loading into the TPF process of MGs, the formability can be remarkably improved, the forming time can be shortened, and the degree of oxidation can be reduced.

However, the underlying mechanism of vibrational loading altering the plastic deformation behavior of MGs is elusive, and much research work is imperative. Hence, based on molecular dynamics (MD) simulations, we studied the mechanical response and microstructure evolution of a Zr-based MG during vibration-assisted tension.

\section{Methods}

\subsection{Model Establishment}

First, a BCC $\mathrm{Zr}$ slab containing 118,656 Zr atoms was built. Then, according to the ratio of $\mathrm{Zr}_{50} \mathrm{Cu}_{46} \mathrm{Al}_{4}$, a part of $\mathrm{Zr}$ atoms are randomly replaced with $\mathrm{Cu}$ and $\mathrm{Al}$ atoms [16]. The resulting system was equilibrated at $2300 \mathrm{~K}$ for $20 \mathrm{ps}$ to achieve the homogeneous distribution of atoms, cooled from $2300 \mathrm{~K}$ to $300 \mathrm{~K}$ at $2 \mathrm{~K} / \mathrm{ps}$, and then re-equilibrated at $300 \mathrm{~K}$ for $20 \mathrm{ps}$. In this process, the NPT ensemble and Nose/Hoover thermostat and barostat algorithms were adopted, and the timestep was set as $0.01 \mathrm{ps}$. The embedded atom method (EAM) potential was used to describe the relationship between atoms [17]. The obtained MG model has a dimension of $2.5 \times 21.0 \times 46.6 \mathrm{~nm}^{3}$, as shown in Figure 1a.
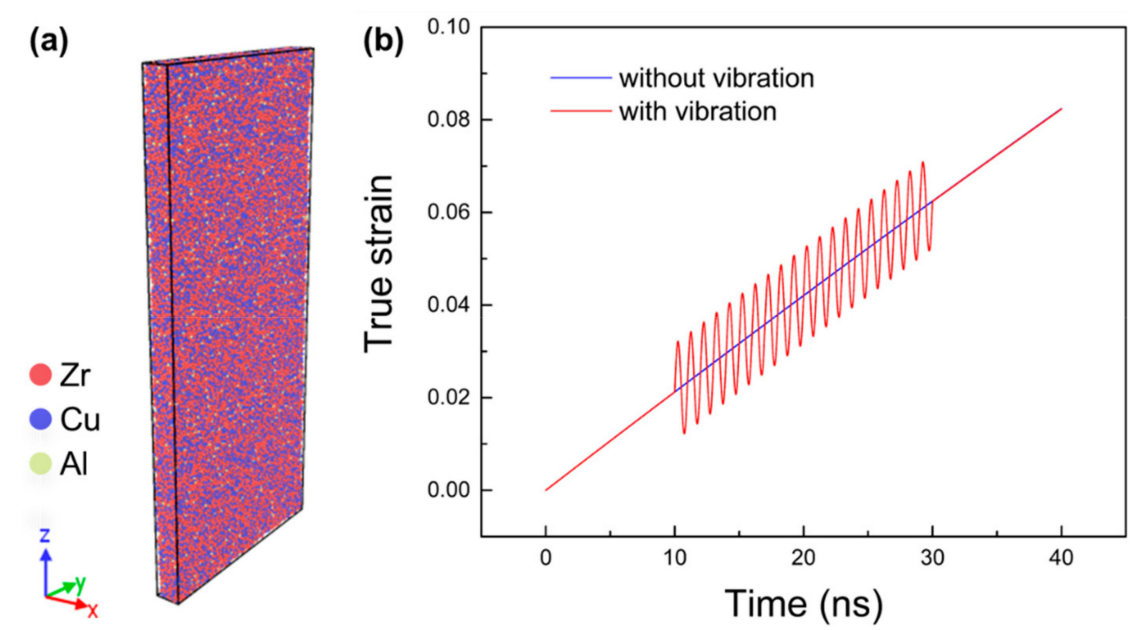

Figure 1. (a) Zr50Cu46Al4 MG model and (b) motion control curve used in molecular dynamics (MD) simulations.

\subsection{Vibration-Assisted Tension}

In order to eliminate the influence of heat generation during deformation and concentrate on the effect of the vibration itself on the deformation behavior, the deformation temperature was set at $50 \mathrm{~K}$. Before the deformation begins, the system was balanced at $50 \mathrm{~K}$ for $20 \mathrm{ps}$. Mixed boundary conditions were employed, i.e., periodic boundary conditions (PBCs) were applied in the $y$ - and $z$ directions, while the $x$-direction was set to a free surface. In other words, the model can be considered as a thin film. The NVT ensemble and the Nose/Hoover thermostat and barostat algorithms were used to control the deformation conditions, and the time step was also set as $0.01 \mathrm{ps}$. 
Uniaxial tension was applied in the $z$-direction and controlled by velocity. The tension velocity was set as $0.1 \mathrm{~nm} / \mathrm{ns}$, and the total deformation duration lasted for $40 \mathrm{~ns}$, that is, the system was elongated by $4 \mathrm{~nm}$ in the $z$-direction, corresponding to a true strain of 0.082 . Vibrational loading was superimposed in the $10 \mathrm{~ns}$ to $30 \mathrm{~ns}$ range, in the form of a sinusoidal wave with a frequency of $1 \mathrm{GHz}$ and an amplitude of $0.05 \mathrm{~nm}$, as shown in Figure 1b. It should be noted that according to our previous attempts, $10 \mathrm{~ns}$ was the starting moment of the yielding stage under this deformation condition. The total number of vibrations was 20 cycles.

Computations were performed by using LAMMPS software (30 Oct 2019 version) running on Tianhe No. 2 supercomputer system (National Supercomputer Center in Guangzhou, China) [18]. Computation results were analyzed and visualized by using the OVITO software (version 3.0.0-dev419) and self-developed Python codes [19].

\section{Results and Discussion}

\subsection{Mechanical Response}

Figure 2a compares the simulated true stress-strain curves of the uniaxial tension processes of MG with or without vibrational loading. After the deformation starts, MG first underwent a linear elastic phase, and the corresponding Young's modulus was $31.13 \mathrm{GPa}$. After reaching a true strain of 0.02, the linear elastic phase ended, and the MG began to yield. For the non-vibrational loading scheme, the true stress-strain curve (in blue color) in the elastoplastic stage was nonlinear and entered the steady flow phase after the true strain of 0.072 . In the case with vibrational loading, the stress-strain curve (in red color) underwent repetitive loading-unloading. Since the amplitude of the vibration was quite small (about $1 \%$ of the length of the initial MG model), the loading stress-strain curve (1, 3 and 5 in Figure $2 b$ ) was mostly linear, indicating that it still lied in the linear elastic phase. Only at the end of loading ( $A$ and B in Figure 2b), apparent yielding occurred. The unloading curve ( 2 and 4 in Figure $2 b$ ) was all within the linear elastic phase. The green line in the insert of Figure 2a shows the average flow stress during the vibrational loading phase, which was mostly similar to that without vibration loading. That is, there was no obvious reduction in the flow stress after imposing vibrational loading, which significantly differed from the softening effect induced by vibrational loading, as reported in previous studies [20,21].

However, after removing the vibrational loading, the flow stress was significantly enhanced. In the simulation range, the yield strength increased from $1.47 \mathrm{GPa}$ to $1.68 \mathrm{GPa}$ in the subsequent deformation process, and the increasing magnitude reached about $14.3 \%$. This indicates that although the vibrational loading applied during the yielding stage failed to reduce the deformation resistance of the MG, it introduced a significant residual hardening effect therein.
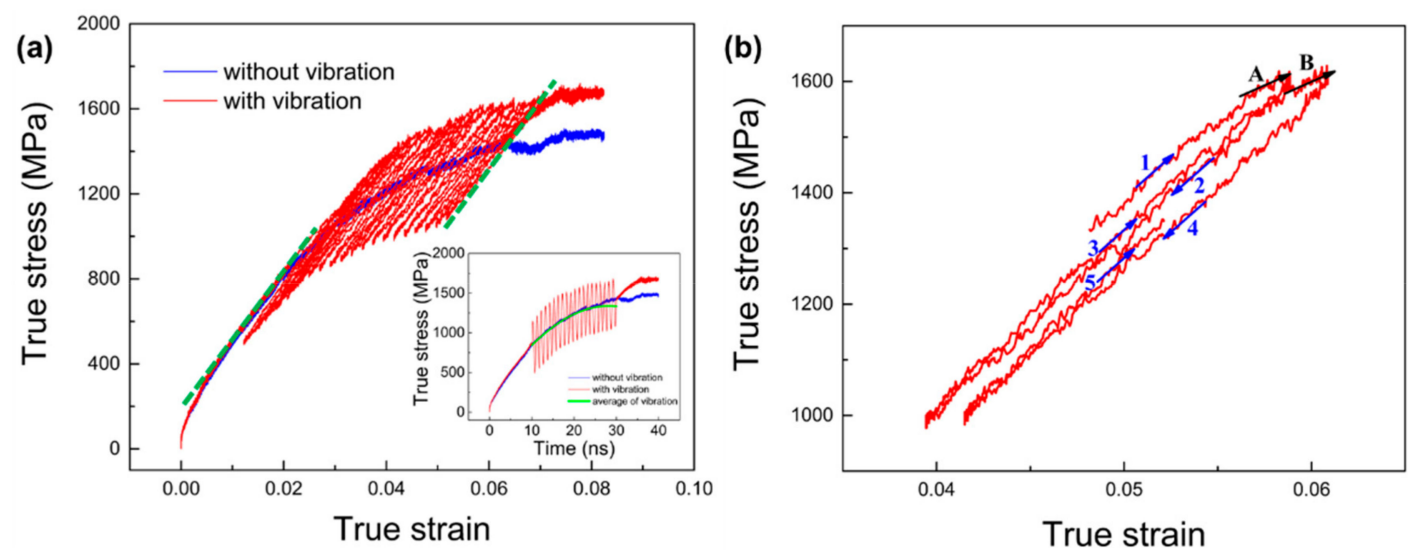

Figure 2. (a) True stress-strain curve and (b) true stress-strain curve partial magnification. 


\subsection{Strain Distribution}

In order to investigate the effect of vibrational loading on the deformation behavior of MGs, we analyzed the local shear strain (also known as von Mises strain) distribution as shown in Figure 3. An atom having a shear strain greater than 0.2 is referred as an $S$ atom, and a cluster of $S$ atoms is defined as a shear transition zone (STZ), so we also call S atoms as STZed atoms [22]. It can be seen from the figure that the distribution of STZs was denser under the action of vibrational loading. Even in the subsequent deformation process after removing vibration, the MG subjected to vibrational loading still had a more intensive internal STZ distribution, comparing to the non-vibrational loaded MG.

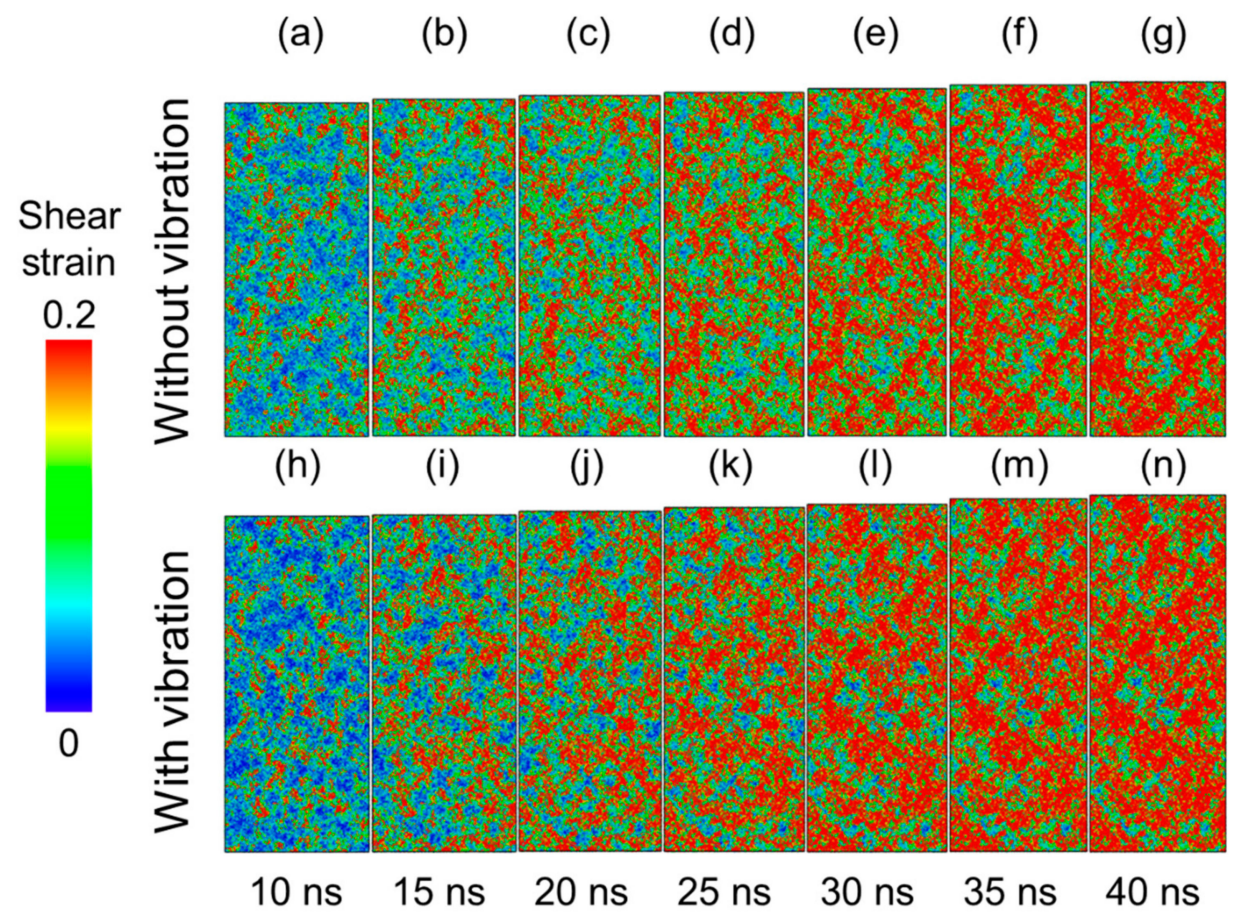

Figure 3. Distribution of shear transition zone (STZs) during the uniaxial tension of MG, (a-g) without vibrational loading and (h-n) with vibrational loading.

To quantitatively characterize the effect of vibrational loading on shear transformation behavior, Figure $4 \mathrm{a}$ depicts the fraction of $\mathrm{S}$ atoms during tension while Figure $4 \mathrm{~b}$ displaying the shear localization factor calculated according to the definition described in our previous study, which is the standard deviation of the local shear strain [23]. It is implied that after imposing the vibrational loading, both the fraction of $S$ atoms and the shear localization factor increase dramatically. A higher shear localization factor indicates a more significant localization degree of deformation. That is, under the action of vibrational loading, more S atoms were shear transformed, more STZs were generated, and the deformation became more localized. The evolution of $S$ atom fraction also presents an obvious synchronous feature with the vibration, i.e., the fraction of $S$ atoms rose quickly in the tensile phase of the vibration cycle while decreased slightly in the compressive phase. Thus, it resulted in the serrated shape of the red-colored curve in Figure 4a. After removing the vibrational loading, the increase of the fraction of $S$ atoms dramatically slowed down, while the shear localization factor directly became nearly constant, during the subsequent non-vibrational loading. Meanwhile, those of the uniaxial tension without vibrational loading kept increasing monotonously and the deviation between two loading schemes gradually decreased. 
(a)

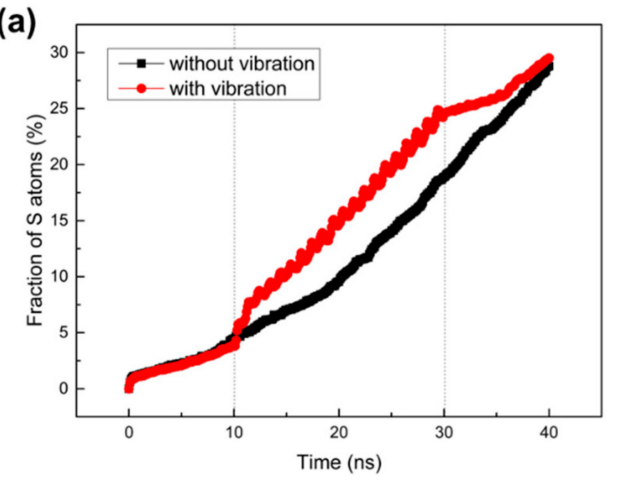

(b)

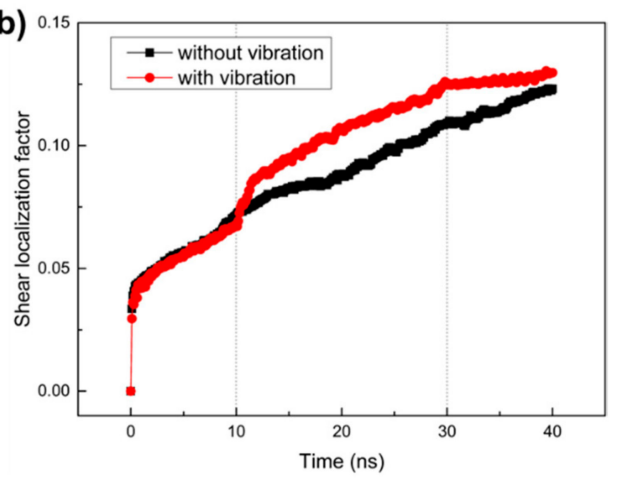

Figure 4. The evolution of (a) the fraction of $\mathrm{S}$ atoms and (b) the shear localization factor during tension.

Figure 5 shows the evolution of the fraction of $S$ atoms in each atom type, which is also calculated based on the definition proposed in our previous work [23]. It is implied that among the three atom types in the $\mathrm{Zr}-\mathrm{Cu}-\mathrm{Al} \mathrm{MG}$ system, $\mathrm{Cu}$ is the most prone to shear transformation, followed by $\mathrm{Al}$ and $\mathrm{Zr}$ in sequence. After imposing vibrational loading, the fraction of STZed atoms in each atom types all experiences sharp increase, with the increase in $\mathrm{Cu}$ as the most prominent.

(a)

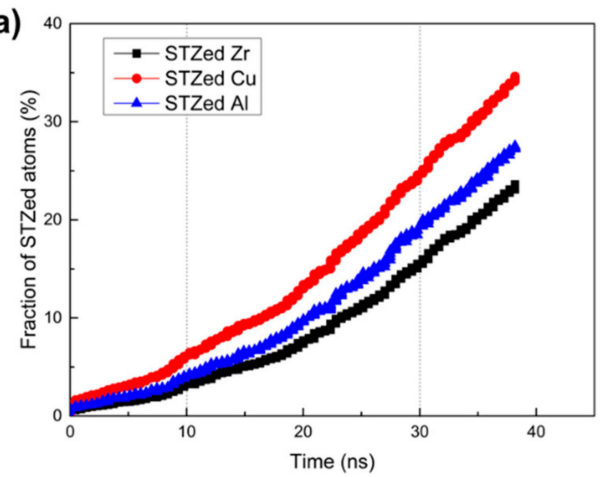

(b)

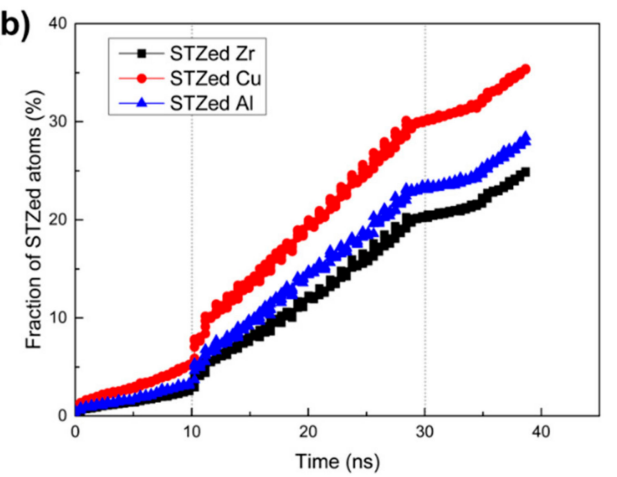

Figure 5. The evolution of the fraction of $S$ atoms in each atom type during tension, (a) without vibrational loading and (b) with vibrational loading.

\subsection{Local Microstructural Evolution}

The icosahedral clusters in MGs have an important influence on the crystallization tendency, glass-forming ability and mechanical properties [24]. Figure 6 compared the evolution of the contents of top-ten icosahedral cluster under two deformation conditions. It was implied that the low coordination number (coordination number of 11-12) icosahedral clusters, including the full icosahedron $<00120>$ and the distorted icosahedra $<028 \quad 1>$ and $<0282>$, were dominant. The low coordination number nature of these clusters experience a discriminable increase makes them more susceptible to deformation [25]. After the imposing vibrational loading, the contents of the $<0281>$ and $<00120>$ clusters were notably increased, while those of other clusters changed little. Since $<00120>$ clusters, especially $\mathrm{Cu}$-centered $<00120>$ clusters, had high packing density and strong shear resistance, the increase of $<00120>$ content would surely lead to the increase of flow resistance. However, when the vibrational loading was removed, the difference in the proportion of these clusters quickly disappeared. 
without vibration

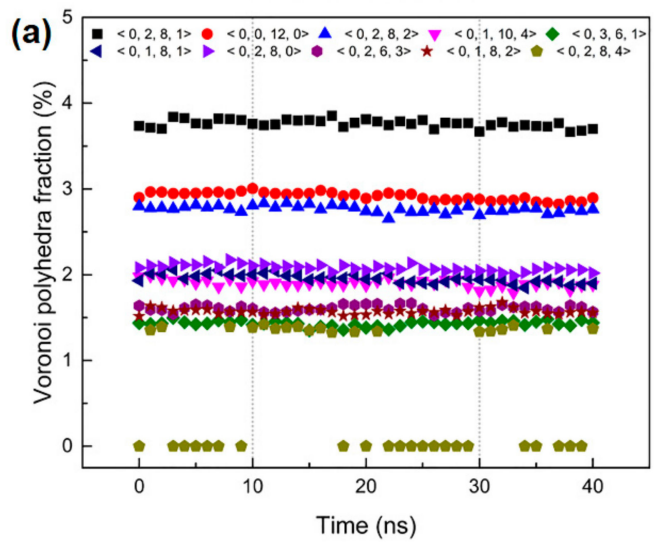

with vibration

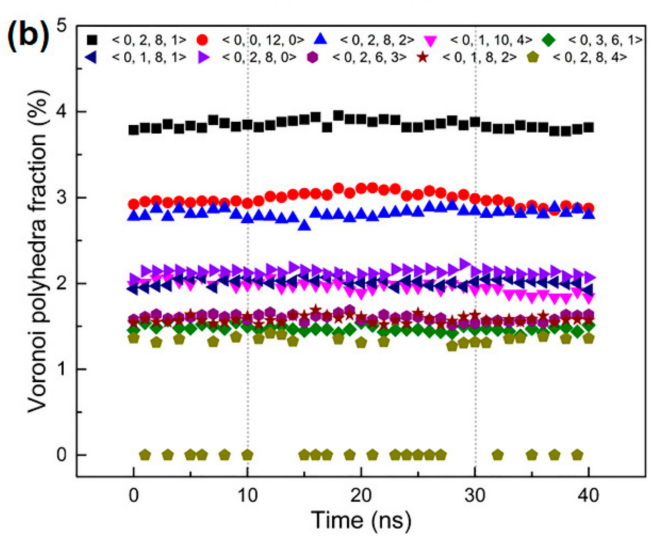

Figure 6. The evolution of Voronoi polyhedra contents during tension, (a) without vibrational loading and (b) with vibrational loading.

Figure 7 shows the radial distribution functions of MGs at different stages of deformation. It can be seen from the figure that there was basically no difference in the radial distribution function at each stage, indicating that the difference in the loading mode had little effect on the spatial structure of the MG [26]. Hence, we could find that the vibration loading under this condition was not strong or severe enough to introduce notable microstructure change of the MG.
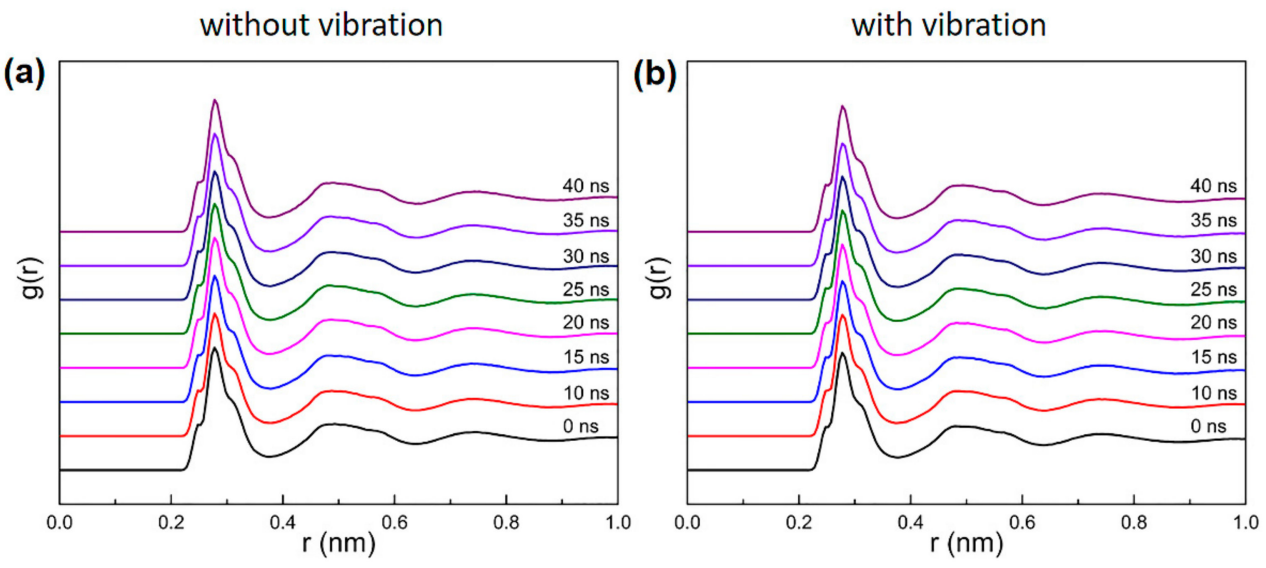

Figure 7. Radial distribution functions of metallic glasses (MGs) during tension, (a) without vibrational loading and (b) with vibrational loading.

As stated above, the vibrational loading imposed during the uniaxial tension had a significant influence on the shear deformation behavior of MG and caused obvious residual hardening effect. Meanwhile, the influence of vibrational loading on the local microstructure of MG was negligible, especially after removing the vibrational loading. Thus, the influencing mechanism of vibrational loading under this condition could not be explained from the aspect of local microstructure change.

Based on nanoindentation tests and simulations, Packard et al. analyzed the strengthening effect of cyclic loading on MG in the elastic range [27]. They found that after several cycles of loading, the sample's deformation resistance increased by $20 \%-30 \%$. They declare that vibrational loading induces locally restricted plasticity inside the material, i.e., forms a locally hardened area inside the material, but cannot be detected by available techniques [28]. Recently, Yu et al. found that under the action of vibration loading with small amplitudes, the MG will experience an accelerated aging process, and they attributed it to the Johari-Goldstein $(\beta)$ relaxation [29]. The aged MGs will be stiffer or stronger than the virgin materials, thus, the residual hardening effect is introduced [30,31]. 


\section{Conclusions}

In this study, the influence of vibrational loading on the deformation behavior of a $\mathrm{Zr}-\mathrm{Cu}-\mathrm{Al}$ MG was characterized via molecular dynamics approaches. The vibrational loading imposed during the uniaxial tension had a significant influence on the shear deformation behavior of MG, by introducing notable residual hardening effect, enhancing the shear transformation degree and increasing the shear localization degree. Meanwhile, the influence of vibrational loading on the local microstructure of MG was negligible, especially after removing the vibrational loading. The residual hardening effect was attributed to the accelerated aging of MGs introduced by vibrational loading.

Author Contributions: Conceptualization, M.Z.; Data curation, Q.L.; Formal analysis, J.J.; Funding acquisition, M.Z., Q.L., X.W. and L.D.; Methodology, J.Z. and L.D.; Project administration, P.G.; Software, Q.L.; Supervision, X.W.; Validation, J.Z.; Visualization, J.J.; Writing-original draft, M.Z.; Writing—review and editing, L.D.

Funding: This work was supported by the National Science Fund for Distinguished Young Scholars of China (grant number 51725504), National Natural Science Foundation of China (grant number 51705168, 51805181, 51675200), and China Postdoctoral Science Foundation (grant number 2017M610473).

Acknowledgments: The authors are grateful for the technical assistance from National Supercomputer Center in Guangzhou.

Conflicts of Interest: The authors declare no conflict of interest.

\section{References}

1. Miller, M.; Liaw, P. Bulk Metallic Glasses: An Overview; Springer: New York, NY, USA, 2008.

2. Suryanarayana, C.; Inoue, A. Bulk Metallic Glasses; CRC Press: Boca Raton, FL, USA, 2011.

3. Wang, W.H.; Dong, C.; Shek, C.H. Bulk metallic glasses. Mater. Sci. Eng. R Rep. 2004, 44, 45-89. [CrossRef]

4. Schroers, J. The superplastic forming of bulk metallic glasses. JOM 2005, 57, 35-39. [CrossRef]

5. Zhang, M.; Yao, D.; Wang, X.; Deng, L. Air oxidation of a Zr55Cu30Al10Ni5 bulk metallic glass at its super cooled liquid state. Corros. Sci. 2014, 82, 410-419. [CrossRef]

6. Wang, X.; Zhang, M.; Deng, L. Oxidation behavior of Zr55Cu30Al10Ni5 BMG under static loading. J. Non Cryst Solids 2017, 469,7-13. [CrossRef]

7. Zhang, M.; Yao, D.; Cao, Z.; Li, P.; Zhou, P.; Wang, X. Influence of oxidation on the performance of Zr55Cu30Al10Ni5 BMG. Intermetallics 2016, 79, 20-27. [CrossRef]

8. Zhang, M.; Zhang, J.; Deng, L.; Li, Q.; Jin, J.; Wang, X. Microstructure evolution of bulk metallic glass during thermal oxidation under plastic strain. Corros. Sci. 2019, 147, 192-200. [CrossRef]

9. Deng, L.; Li, P.; Wang, X.; Zhang, M.; Li, J. Influence of low-frequency vibrations on the compression behavior and microstructure of T2 copper. Mater. Sci. Eng. A 2018, 710, 129-135. [CrossRef]

10. Li, N.; Liu, Z.; Wang, X.; Zhang, M. Vibration-accelerated activation of flow units in a Pd-based bulk metallic glass. Mater. Sci. Eng. A 2017, 692, 62-66. [CrossRef]

11. Bai, Y.; Yang, M. The influence of superimposed ultrasonic vibration on surface asperities deformation. J. Mater. Process. Technol. 2016, 229, 367-374. [CrossRef]

12. Han, G.; Li, K.; Peng, Z.; Jin, J.; Sun, M.; Wang, X. A new porous block sonotrode for ultrasonic assisted micro plastic forming. Int. J. Adv. Manuf. Technol. 2017, 89, 2193-2202. [CrossRef]

13. Zhang, M.; Li, P.; Yao, D.; Deng, L.; Jin, J.S.; Wang, X.Y. Investigation on upsetting assisted by low-frequency vibration. In Proceedings of the International Conference on New Forming Technology, Scotland, UK, 6-8 August 2015; EDP Sciences: Les Ulis, France, 2015.

14. Li, N.; Xu, X.; Zheng, Z.; Liu, L. Enhanced formability of a Zr-based bulk metallic glass in a supercooled liquid state by vibrational loading. Acta Mater. 2014, 65, 400-411. [CrossRef]

15. Ma, J.; Liang, X.; Wu, X.; Liu, Z.; Gong, F. Sub-second thermoplastic forming of bulk metallic glasses by ultrasonic beating. Sci. Rep. 2015, 5, 17844. [CrossRef] [PubMed]

16. Hirel, P. Atomsk: A tool for manipulating and converting atomic data files. Comput. Phys. Commun. 2015, 197, 212-219. [CrossRef]

17. Cheng, Y.Q.; Ma, E.; Sheng, H.W. Atomic level structure in multicomponent bulk metallic glass. Phys. Rev. Lett. 2009, 102, 245501. [CrossRef] 
18. Plimpton, S. Fast parallel algorithms for short-range molecular dynamics. J. Comput. Phys. 1995, 117, 1-19. [CrossRef]

19. Alexander, S. Visualization and analysis of atomistic simulation data with OVITO-the Open Visualization Tool. Modell. Simul. Mater. Sci. Eng. 2010, 18, 15012.

20. Khan, A.; Giraud-Audine, C.; Bigot, R.; Abba, G.; Abideen, M.Z. An alternative explanation of forming force reduction for forming process submitted to vibration: Influence of the waveform in the viscoplastic domain. J. Mater. Process. Technol. 2016, 230, 288-299. [CrossRef]

21. Yao, Z.; Kim, G.; Faidley, L.; Zou, Q.; Mei, D.; Chen, Z. Acoustic softening and hardening of aluminum in high-frequency vibration-assisted micro/meso forming. Mater. Manuf. Process. 2013, 28, 584-588. [CrossRef]

22. Sha, Z.D.; Qu, S.X.; Liu, Z.S.; Wang, T.J.; Gao, H. Cyclic deformation in metallic glasses. Nano Lett. 2015, 15, 7010-7015. [CrossRef]

23. Zhang, M.; Li, Q.; Zhang, J.; Zheng, G.; Wang, X. The prominent combination of ultrahigh strength and superior tensile plasticity in $\mathrm{Cu}-\mathrm{Zr}$ nanoglass connected by oxide interfaces: A molecular dynamics study. J. Alloys Compd. 2019, 801, 318-326. [CrossRef]

24. Yang, M.H.; Li, J.H.; Liu, B.X. Comparatively studying the local atomic structures of metallic glasses upon cyclic-loading by computer simulations. RSC Adv. 2017, 7, 18358-18365. [CrossRef]

25. Adibi, S.; Sha, Z.; Branicio, P.S.; Joshi, S.P.; Liu, Z.; Zhang, Y. A transition from localized shear banding to homogeneous superplastic flow in nanoglass. Appl. Phys. Lett. 2013, 103, 211905. [CrossRef]

26. Mattern, N.; Schoeps, A.; Kuehn, U.; Acker, J.; Khvostikova, O.; Eckert, J. Structural behavior of $\mathrm{Cu}_{x} \mathrm{Zr}_{100-x}$ metallic glass $(x=35-70)$. J. Non Cryst. Solids 2008, 354, 1054-1060. [CrossRef]

27. Packard, C.E.; Homer, E.R.; Al-Aqeeli, N.; Schuh, C.A. Cyclic hardening of metallic glasses under Hertzian contacts: Experiments and STZ dynamics simulations. Philos. Mag. 2010, 90, 1373-1390. [CrossRef]

28. Packard, C.E.; Witmer, L.M.; Schuh, C.A. Hardening of a metallic glass during cyclic loading in the elastic range. Appl. Phys. Lett. 2008, 92, 171911. [CrossRef]

29. Zhou, Z.; Peng, H.; Yu, H. Structural origin for vibration-induced accelerated aging and rejuvenation in metallic glasses. J. Chem. Phys. 2019, 150, 204507. [CrossRef]

30. Qiao, J.C.; Pelletier, J.M. Dynamic mechanical relaxation in bulk metallic glasses: A review. J. Mater. Sci. Technol. 2014, 30, 523-545. [CrossRef]

31. Wang, W.H. The elastic properties, elastic models and elastic perspectives of metallic. Prog. Mater. Sci. 2012, 57, 487-656. [CrossRef] 